\section{Research Square}

\title{
High Urinary Sodium Excretion Is Associated with Synchronous Gastric Epithelial Neoplasms in Women
}

\section{Dong Hyun Kim}

Chonnam National University Medical School

Seon-Young Park ( $\nabla$ drpsy@naver.com)

Chonnam National Universitiy Hospital

Jin Ook Chung

Chonnam National University Medical School

Ji Ho Seo

Chonnam National University Hospital

Hyun A Cho

Chonnam National University Hospital

Ji-Yun Hong

Chonnam National University Hospital

Chang Hwan Park

Chonnam National University Medical School

Hyun Soo Kim

Chonnam National University Medical School

\section{Sung Kyu Choi}

Chonnam National University Medical School Jong Sun Rew

Chonnam National University Medical School

\section{Research article}

Keywords: Neoplasms, Multiple Primary, Risk Factors, Sodium, Stomach Neoplasms, Women

Posted Date: January 22nd, 2020

DOI: https://doi.org/10.21203/rs.2.21606/v1

License: (c) (i) This work is licensed under a Creative Commons Attribution 4.0 International License. Read Full License 


\section{Abstract}

Background : Although previous studies have suggested a high salt intake as a risk factor for precancerous and cancerous lesions of stomach, the evidence is not sufficient to draw a conclusion yet. We aimed to evaluate the association between 'estimated 24-hour urinary sodium excretion' and prevalence of synchronous gastric epithelial neoplasm.

Methods: Among 2017 patients with gastric epithelial neoplasms, who had test results for estimated 24hour urinary sodium excretion, 1310 were enrolled.

Results: There were $545(41.6 \%)$ patients with high-grade dysplasia and early gastric cancer. The mean age was 64.5 years; 853 (65.1\%) were men and 244 (18.6\%) were smokers. The rate of Helicobacter pylori infection was $71.0 \%$ (797/1123). The incidence of synchronous gastric epithelial neoplasm was $10.6 \%$ (139/1310). Significant interactions were seen between estimated 24-hour urine sodium' and sex ( $P$ interaction $=0.003$ ), with the association largely limited to women; 'estimated 24-hour urine sodium' (aOR, $1.26 ; 95 \% \mathrm{Cl}, 1.05$ to $1.51, \mathrm{P}=0.012$ ) was an independent risk factor for synchronous gastric neoplasm in women.

Conclusions: High 'estimated 24-hour urinary sodium excretion' was associated with synchronous gastric epithelial neoplasm in women.

\section{Background}

Gastric cancer is a very common disease worldwide and one of the major causes of cancer-related death. ${ }^{1}$ It has significant geographic, ethnic, and socioeconomic differences in distribution, which suggest that environmental factors have an important role in the development of gastric cancer. Among these environmental factors, many studies have reported that a high salt intake and preference for salty taste might be associated with an increased risk of gastric cancer; ${ }^{2-6}$ however, the results are inconsistent. In a US cohort study, a high intake of salted food was positively associated with the risk of gastric cancer, ${ }^{7}$ where as in a Japanese cohort study, a high intake of salted foods was not associated with the risk of gastric cancer. ${ }^{8}$ Furthermore, a recent meta-analysis showed that an association between salt intake and gastric precancerous lesions was statistically non-significant. ${ }^{9}$ Therefore, the evidence of association between salt intake and gastric cancerous or precancerous lesions is insufficient to draw a conclusion.

Methods of measurement for salt intake include 24-hour urinary sodium excretion and dietary assessment of salty preference and salty food intake. ${ }^{2} 81011$ Among these methods, the 24-hour urinary sodium excretion closely reflects ingested salt and is considered the gold standard for measuring salt intake. However, it is not simple and cost-effective to measure 24-hour urinary sodium. Therefore, estimating sodium intake from spot urine samples has been suggested. ${ }^{10} 12-14$

Nowadays, minimally invasive techniques such as endoscopic mucosal resection or endoscopic submucosal dissection have been performed for early stages of diseases. Therefore, it is important to 
detect the synchronous and/or metachronous lesions around the time of treatment in patients with high risk for gastric cancer. Therefore, we aimed to evaluate the association between 'estimated 24-hour

urinary sodium excretion (e-24hr- $\left.\mathrm{U}_{\text {sodium }}\right)$ ' and the incidence of synchronous lesions in patients with gastric epithelial neoplasms (GENs).

\section{Methods}

\section{Study population}

The present study was conducted in accordance with the Ethical Guidelines of the Declaration of Helsinki. This study was approved by the Institutional Review Board of Chonnam National University Hospital (No. CNUH-2017-279). Informed written consent for management and follow-up for gastric epithelial neoplasm was obtained from all participants.

In our center, since 2011, we have calculated 'e-24hr-U $U_{\text {sodium }}$ ' using spot urine samples for patients with GEN who underwent endoscopic resection (endoscopic mucosal resection and/or endoscopic submucosal dissection). We identified a cohort of 2017 patients who underwent endoscopic resection for GEN and for whom test results for e-24hr-Usodiumwere available between March 1, 2011, and March 1, 2017. We excluded 425 patients who had a serum creatinine level $>1.3 \mathrm{mg} / \mathrm{dL}$ and who were taking diuretics. We also excluded 282 patients who underwent endoscopic resection for pathologic lesions other than GEN. Finally, 1310 patients were enrolled in this study (Fig. 1). After endoscopic resection for GEN, follow-up endoscopy was scheduled at the 3rd, 6th, and 12th month and yearly thereafter. We collected information about the patients' demographic and clinical characteristics.

\section{Estimation of 24-hour urinary sodium excretion}

We used 'e-24hr- $U_{\text {sodium' }}$ assessed in spot urine to evaluate the degree of salt intake ${ }^{15}$. We used the two estimation formula from the sodium of random urine samples (Tanaka equation and Kawasaki equation) as follows; ${ }^{10} 12$

24-hour urinary sodium excretion (mmol/day) by Kawasaki ${ }^{10}=16.3 \times\left(\mathrm{U}_{\text {Sodium }} / \mathrm{U}_{\text {Creatinine }} \times[15.12 \times\right.$ Weight $(\mathrm{kg})+7.36$ Height $(\mathrm{cm})-12.63 \times$ age-79.9] $)^{0.5}(\mathrm{Man})$ or $16.3 \times\left(\mathrm{U}_{\text {Sodium }} / \mathrm{U}_{\text {Creatinine }} \times[8.58 \times\right.$ Weight $(\mathrm{kg})+5.09$ $\times$ Height $(\mathrm{cm})-4.72 \times$ age -74.95$])^{0.5}($ Woman)

24-hour urinary sodium excretion ( $\mathrm{mmol} /$ day) by Tanaka ${ }^{12}=21.98 \times\left(\mathrm{U}_{\text {Sodium }} / \mathrm{U}_{\text {Creatinine }} \times[-2.04 \times\right.$ age + $14.89 \times$ weight $(\mathrm{kg})+16.14 \times$ height $(\mathrm{cm})]-2244.45)^{0.392}$

\section{Definition of synchronous gastric epithelial neoplasm}

We defined synchronous GENs as dysplasia or carcinoma at another site in the stomach within 1 year after endoscopic resection of the primary lesion. 


\section{Statistical analysis}

The statistical analysis was performed using SPSS version 23.0 (SPSS Inc., Chicago, IL, USA). Continuous data are shown as mean \pm standard deviation or median (range), while categorical data are shown as absolute and relative frequencies. The continuous variables of synchronous lesions were analyzed using Student's t-test. Categorical data were examined using Fisher's exact test or $x^{2}$ test. On multivariate analysis, binary logistic regression models with enter were used to investigate the risk factors associated with synchronous lesions. The data included in the regression analysis are presented as crude or adjusted odds ratios (cORs or aORs) with 95\% confidence intervals (Cls). Correlation between 'e-24hr$\mathrm{U}_{\text {sodium }}$ ' by Tanaka's equation and by' Kawasaki's equation was performed using non-parametric rank correlation (Spearman correlation, Rs).

The interaction terms of the clinical factors including age, sex and BMI with ' $\mathrm{e}-24 \mathrm{hr}-\mathrm{U}_{\text {sodium }}$ ' were included to evaluate the distinctive associations across ' $\mathrm{e}-24 \mathrm{hr}-\mathrm{U}_{\text {sodium'. When a significant interaction was }}$ detected, a stratified analysis was further conducted to determine the OR. Variables with a P value $<0.05$ in the univariate analysis were selected for possible inclusion in the multivariate analysis.

\section{Results}

\section{Patient demographics}

Figure 1 shows a flow chart of the patient cohort starting with 2017 medical records. Eventually, 1310 patients were included in this study. There were 765 (58.4\%) patients with low-grade dysplasia, 245 (18.7\%) patients with high grade dysplasia, $289(22.1 \%)$ patients with differentiated adenocarcinoma, and $11(0.8 \%)$ patients with undifferentiated adenocarcinoma. The mean age was 64.5 years; $853(65.1 \%)$ were men and $244(18.6 \%)$ were past or current smokers. The rate of Helicobacter pylori infection was $71.0 \%$ (797/1123, Table 1). Median follow-up duration was 12 months (range, 0-166 months). 
Table 1

Demographics of 1310 patients with gastric epithelial neoplasms

\begin{tabular}{|c|c|c|c|c|}
\hline & $\begin{array}{l}\text { Total } \\
(\mathrm{N}= \\
1310)\end{array}$ & $\begin{array}{l}\text { Patients with } \\
\text { synchronous gastric } \\
\text { neoplasm } \\
(n=139)\end{array}$ & $\begin{array}{l}\text { Patients without } \\
\text { synchronous gastric } \\
\text { neoplasm } \\
(n=1171)\end{array}$ & $\begin{array}{l}P \\
\text { value }\end{array}$ \\
\hline Age, years, mean $\pm S D$ & $64.5 \pm 9.7$ & $66.8 \pm 9.7$ & $64.2 \pm 9.7$ & 0.003 \\
\hline Sex & & & & 0.001 \\
\hline Women, n (\%) & $\begin{array}{l}457 \\
(34.9)\end{array}$ & $31(6.8)$ & $426(93.2)$ & \\
\hline Men, n (\%) & $\begin{array}{l}853 \\
(65.1)\end{array}$ & $108(12.7)$ & $745(87.3)$ & \\
\hline $\begin{array}{l}\mathrm{BMI}, \mathrm{kg} / \mathrm{m}^{2} \text {, mean } \pm \\
\mathrm{SD}\end{array}$ & $24.1 \pm 3.0$ & $24.3 \pm 2.9$ & $24.1 \pm 3.0$ & 0.461 \\
\hline $\begin{array}{l}\text { Past or current } \\
\text { smoker, } \mathrm{n}(\%)\end{array}$ & $\begin{array}{l}244 \\
(18.6)\end{array}$ & $29(20.9)$ & $215(18.4)$ & 0.492 \\
\hline Hypertension, n (\%) & $\begin{array}{l}401 \\
(30.6)\end{array}$ & $56(40.3)$ & 345 (29.5) & 0.009 \\
\hline Diabetes, n (\%) & $80(6.1)$ & $7(5.0)$ & $73(6.2)$ & 0.577 \\
\hline $\begin{array}{l}\text { H. pylori infection, } n \\
(\%)\end{array}$ & $\begin{array}{l}797 / 1123 \\
(71.0)\end{array}$ & $87 / 123(70.7)$ & $710 / 1000(71.0)$ & 0.951 \\
\hline $\begin{array}{l}\text { 'e-24hr-U } \text { sodium }(\mathrm{K}) \text { ', } \\
\mathrm{mmol} / \text { day, mean } \pm \text { SD }\end{array}$ & $\begin{array}{l}180.4 \pm \\
55.2\end{array}$ & $178.5 \pm 61.0$ & $180.6 \pm 54.5$ & 0.694 \\
\hline $\begin{array}{l}\text { 'e-24hr-U } U_{\text {sodium }}(T) \text { ', } \\
\mathrm{mmol} / \text { day, mean } \pm \mathrm{SD}\end{array}$ & $\begin{array}{l}394.8 \pm \\
96.8\end{array}$ & $395.4 \pm 108.2$ & $394.7 \pm 95.4$ & 0.931 \\
\hline \multicolumn{5}{|c|}{$\begin{array}{l}\text { SD, standard deviation; BMI, body mass index; } \mathrm{H} \text {. pylori, Helicobacter pylori; 'e-24hr- } \mathrm{U}_{\text {sodium }}(\mathrm{K}) \text { ', } \\
\text { estimated } 24 \text {-hour urinary sodium excretion by Kawasaki's equation; 'e-24hr- } \mathrm{U}_{\text {sodium }}(\mathrm{T})^{\prime} \text {, estimated } 24- \\
\text { hour urinary sodium excretion by Tanaka's equation }\end{array}$} \\
\hline
\end{tabular}

\section{Correlation between two methods of 'estimated 24-hour urinary sodium excretion'}

We used two equations to get 'e-24hr- $\mathrm{U}_{\text {sodium }}$. Mean 'e-24hr- $\mathrm{U}_{\text {sodium }}$ ' by Kawasaki's equation and Tanaka's equation was $180.4 \pm 55.2 \mathrm{mmol} /$ day and $394.8 \pm 96.8 \mathrm{mmol} /$ day, respectively. The 'e- $24 \mathrm{hr}-\mathrm{U}_{\text {sodium }}$ ' by Kawasaki's equation was correlated with the 'e-24hr- $U_{\text {sodium }}$ ' by Tanaka's equation (Rs $=0.956, P<0.001$, Fig. 2). 


\section{Synchronous gastric epithelial neoplasms}

The incidence of synchronous GENs was 10.6\% (139/1310). We identified synchronous GENs before or at the time of endoscopic resection in 82 patients (59\%). In the remaining 57 patients (41\%), synchronous GENs were diagnosed within 1 year after endoscopic resection of the primary lesion.

We evaluated clinical risk factors for patients with synchronous GENs. The incidence of synchronous GENs was higher in men $(108 / 853,12.7 \%)$ than in women $(31 / 457,6.8 \% ; P=0.001)$. The mean age $(66.8$ \pm 9.7 years) of the patients with synchronous GENs was higher than that of patients without synchronous GENs (64.2 \pm 9.7 years, $p=0.003$ ). Patients with synchronous GENs had a higher prevalence of hypertension (40.3\%) than those without synchronous GENs $(29.5 \%, P=0.009)$. There was no difference in body mass index, 'e-24hr- $U_{\text {sodium }}$ ' by Kawasaki' equation or Tanaka's equation, or H. pylori infection status between patients with synchronous GENs and patients without synchronous GENs (Table 1).

Multivariate analysis of these variables showed that age $(a O R, 1.03 ; 95 \% \mathrm{Cl}, 1.01$ to $1.05 ; \mathrm{P}=0.011)$, men $(\mathrm{aOR}, 2.11 ; 95 \% \mathrm{Cl}, 1.38$ to $3.20 ; \mathrm{P}=0.001)$, and hypertension $(\mathrm{aOR}, 1.46 ; 95 \% \mathrm{Cl}, 1.01$ to $2.13 ; \mathrm{P}=0.047$ ) were independent risk factors for synchronous GENs.

\section{Synchronous gastric epithelial neoplasms by sex}

As a significant interaction with 'e-24hr- $U_{\text {sodium }}$ ' and sex was detected (P-interaction $\left.=0.003\right)$, a stratified analysis by sex was conducted.

When stratified by sex, the association between 'e-24hr- $U_{\text {sodium' }}$ and synchronous GEN was statistically significant for women, but not for men (Table 2,3$)$. In women $(n=457)$, patients with synchronous GEN had higher 'e-24hr- $U_{\text {sodium }}$ 'than those without synchronous GEN (Table 2). In women, 'e-24hr- $U_{\text {sodium }}$ (any $50 \mathrm{mmol}$ increase/day)' by Tanaka's equation was associated with synchronous $\mathrm{GEN}$ (COR, $1.22 ; 95 \% \mathrm{Cl}$, 1.04 to 1.44). Further adjustment for age, BMI, and other clinical factors did not change the results (Table 3). 
Table 2

Clinical Differences according to the presence of synchronous gastric epithelial neoplasm by sex

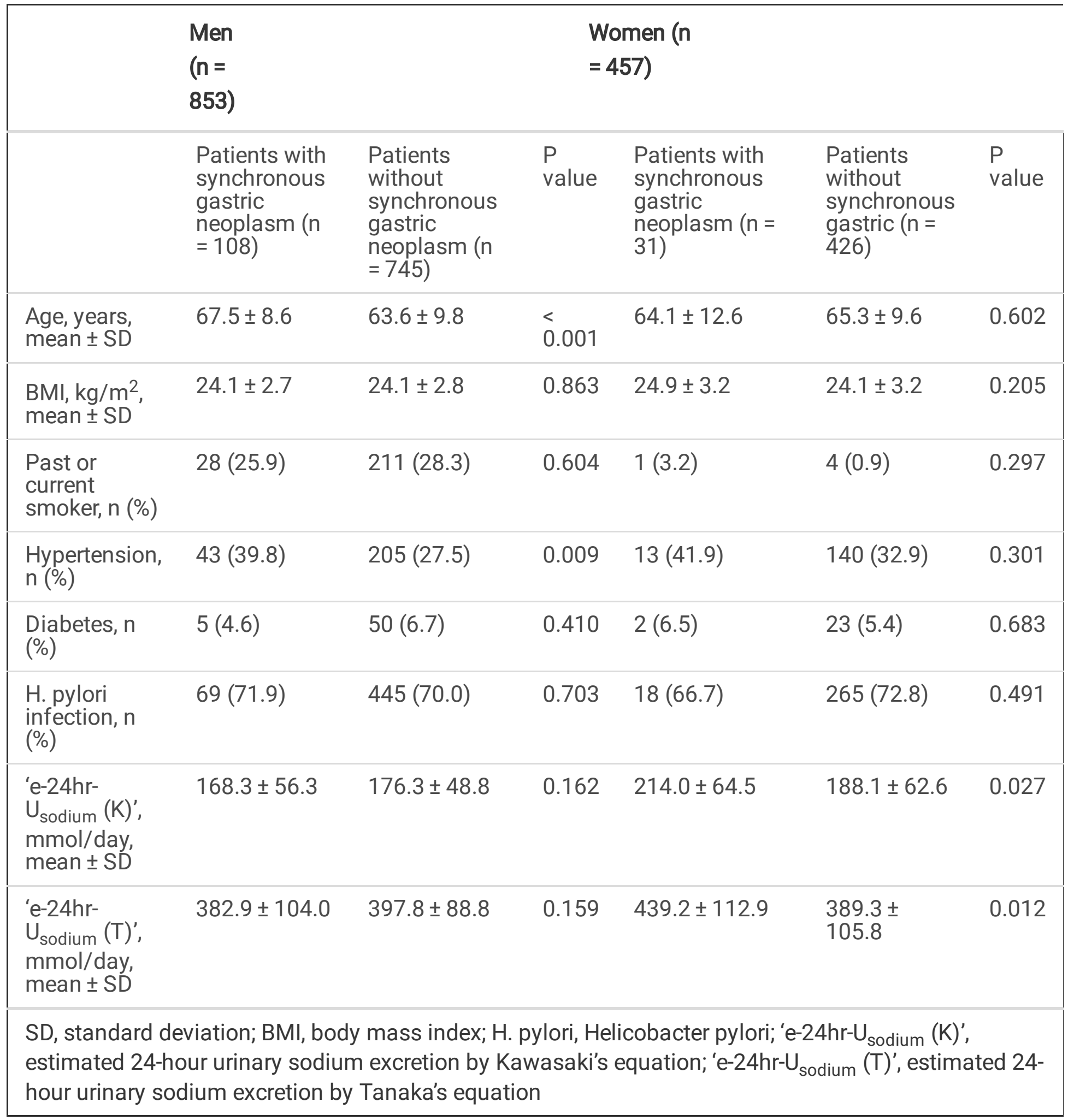


Table 3

Logistic regression models of the association between 'Estimated 24-hour urinary sodium excretion' and synchronous gastric epithelial neoplasm

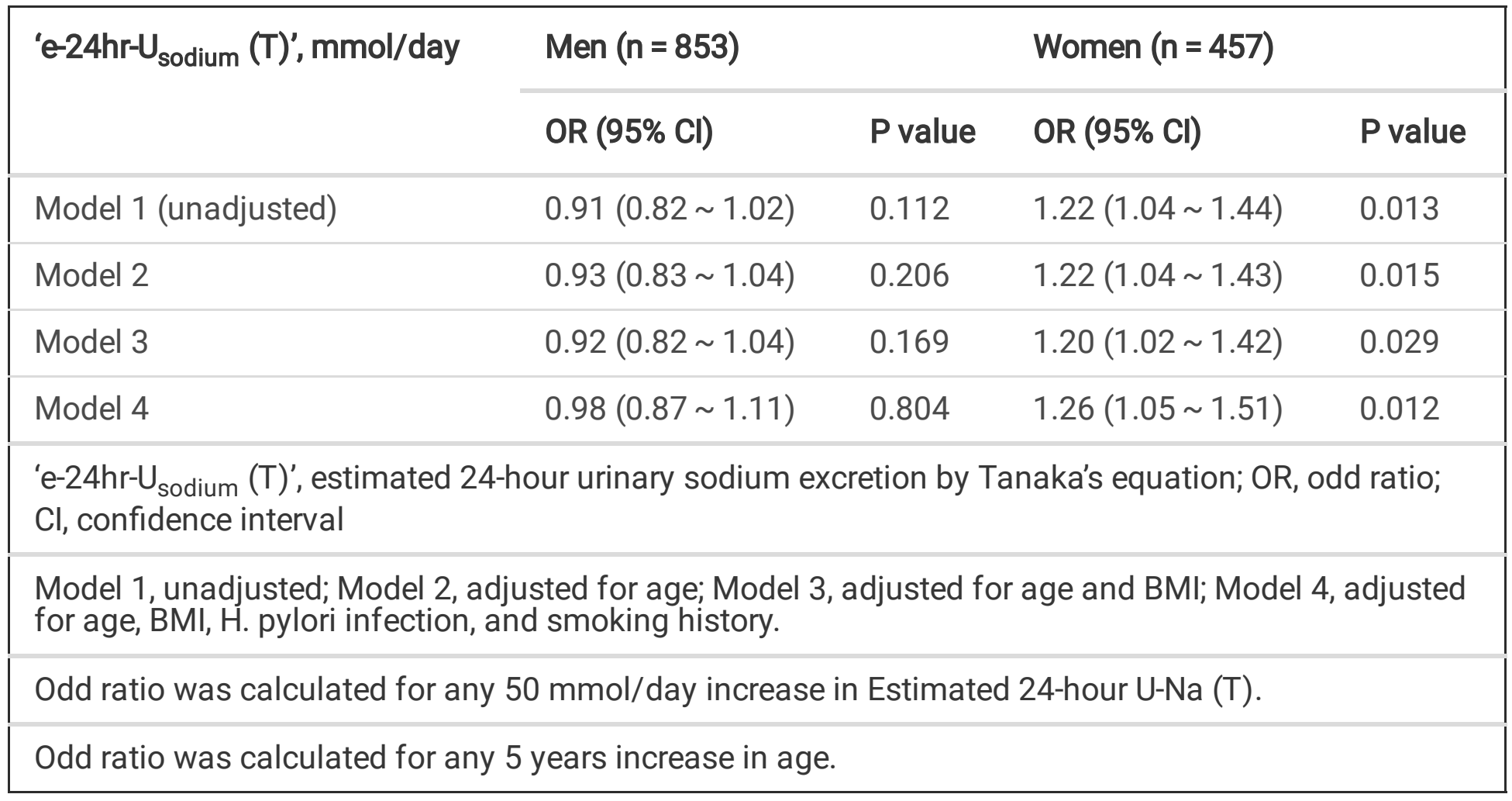

Among 545 patients with high grade dysplasia and adenocarcinoma, men $(64 / 369,17.3 \%)$ had higher incidence of synchronous GENs than in women $(15 / 176,8.5 \% ; P=0.006)$. Since there was an interaction between sex and 'e-24hr- $\mathrm{U}_{\text {sodium }}$ ' (P-interaction $\left.=0.003\right)$, we evaluated the clinical risk factors by sex. When stratified by sex, 'e- $24 \mathrm{hr}-\mathrm{U}_{\text {sodium }}$ (any $50 \mathrm{mmol}$ increase/day)' by Tanaka's equation was an independent risk factor for synchronous GENs in women (aOR, 1.51; $95 \% \mathrm{Cl}, 1.17$ to $1.95 ; \mathrm{P}=0.001)$, but not in men.

\section{Discussion}

In this study, we aimed to investigate the association between ' $\mathrm{e}-24 \mathrm{hr}-\mathrm{U}_{\text {sodium' }}$ ' and the incidence of synchronous lesions in patients with GENs. A statistically significant interaction was found between 'e$24 \mathrm{hr}-\mathrm{U}_{\text {sodium }}$ ' and sex (P-interaction $\left.=0.003\right)$, with the relation largely limited to women; ' $\mathrm{e}-24 \mathrm{hr}-\mathrm{U}_{\text {sodium }}$ ' was significantly and positively associated with synchronous GENs in women, but not in men. In addition, we identified the clinical risk factors such as male sex, age, and hypertension for synchronous lesions in patients with GEN.

Since endoscopic resection is a local method for managing GEN, it is important to find synchronous lesions before endoscopic resection and synchronous and/or metachronous lesions after endoscopic resection. We showed that $10.6 \%$ of patients had synchronous GENs, a similar incidence to those of previous studies. ${ }^{16-19}$ Clinicians need to perform meticulous endoscopic examination, especially in 
patients with lifestyle-related risk factors such as a high-salt diet, obesity, and smoking. ${ }^{20}$ We identified the clinical factors such as male sex, age, and hypertension for synchronous lesions in patients with GEN. A previous study showed that old age ( $\geq 65$ years) was associated with synchronous gastric cancers. ${ }^{21}$ Another study demonstrated that the incidence of precancerous lesions such as intestinal metaplasia was increased in the gastric mucosa of elderly patients. ${ }^{22}$ We also showed a sex-based difference in the incidence of synchronous lesions in patients with GEN, which has been explained by variable environmental factors including smoking, alcohol, different dietary factors, and hormones such as estrogen..$^{23-26}$

We identified a significant association between 'e-24hr- $U_{\text {sodium }}$ ' and synchronous GENs, which was in line with previous studies. ${ }^{5} 62728$ However, the association between 'e-24hr- $U_{\text {sodium' }}$ and synchronous GENs was largely limited to women, and there is currently little information about salt intake and sex-based difference of carcinogenesis. Instead, there were several studies suggesting a sex-based or menopausal status-based difference in salt-sensitive hypertension ${ }^{29-32}$. There were some studies showing sexdifference regarding the effect of obesity and dyslipidemia on gastric cancerous or precancerous lesion. ${ }^{33} 34$ Kim et al demonstrated that obesity was associated with increased risk of early gastric cancer in men and was associated with gastric dysplasia in women. ${ }^{33}$ Another study showed that BMI was associated with an increased risk of gastric high grade dysplasia in men and women, whereas a higher serum total cholesterol level was associated with gastric high-grade dysplasia in women. ${ }^{34}$ Therefore, future studies are needed to be clarified for this difference.

We used two equation formulas to estimate 24-hour urinary sodium excretion. Measurement 24-hour urinary sodium excretion is a more objective method for evaluation of salt intake than dietary assessment of salty preference and salty food intake, which are dependent on patient's recall memories. However, it is not simple and cost-effective to measure 24-hour urinary sodium in all patients. Therefore, various methods for estimating sodium intake from spot urine samples have been suggested. ${ }^{35-39}$ We used Kawasaki's equation and Tanaka's equation, which are simple and were validated in Asian population. 510 1240 'e-24hr- $U_{\text {sodium }}$ ' correlates with measured 24-hour urinary sodium excretion,, 13 especially in subjects with a high salt intake. ${ }^{12}$ Recently, 'e-24hr-U $U_{\text {sodium' }}$ has known to be associated with cardiovascular disease, obesity, metabolic syndrome, and cancer and mortality. ${ }^{36-39}$ 41-43 In this study, the value of 'e$24 \mathrm{hr}-\mathrm{U}_{\text {sodium }}$ ' by Kawasaki's equation tended to be lower that by Tanaka's equation. However, we found a high correlation between Kawasaki's equation and Tanaka's equation in estimation of 24-hour urinary sodium excretion.

This study has limitation of retrospective cohort study. However, we applied to the same methodology of history taking, urinary sample collection and endoscopic resection to all enrolled patients.

\section{Conclusion}


In conclusion, our findings demonstrated that 'e-24hr- $\mathrm{U}_{\text {sodium' }}$ ' was associated with synchronous GEN in women. In the future, we need to evaluate the pathophysiology or molecular mechanism of sex-based differences in gastric carcinogenesis and investigate the preventive role of salt restriction in the incidence of metachronous lesions in patients treated for GENs.

\section{List Of Abbreviations}

aORs adjusted odd ratio

BMI body mass index

Cl confidence interval

cOR crude odds ratio

e-24hr- $U_{\text {sodium }}$ estimated 24 -hour urinary sodium excretion

GEN gastric epithelial neoplasm

H. pylori Helicobacter pylori

SD standard deviation

OR odds ratio

\section{Declarations}

\section{Ethics approval and consent to participate}

This study was approved by the Institutional Review Board of Chonnam National University Hospital (No. CNUH-2017-279). Informed written consent for management and follow-up for gastric epithelial neoplasm was obtained from all participants.

\section{Consent for publication}

Not applicable.

\section{Availability of data and materials}

The datasets utilized and/or reviewed throughout the present study can be obtained from the corresponding author on sensible request.

\section{Competing interests}

Authors declare that they have no competing interests. 


\section{Funding:}

This research was supported by the National Research Foundation of Korea (NRF) grant funded by the Korea government (2018R1C1B5043483) and the Korean College of Helicobacter and Upper Gastrointestinal Research Foundation Grant.

\section{Authors' contributions:}

DHK: analysis of electronic medical records; drafting the manuscript

SYP: study concept and design; analysis and interpretation of data; drafting and finalizing the manuscript; study supervision

JOC: interpretation of data; drafting the manuscript

JHS, HAC and JYH: collection and assembly of data, analysis of electronic medical record

CHP, HSK, SKC and JSR: patient recruitment and care

\section{Acknowledgements}

Not applicable.

\section{References}

1 Jemal A, Bray F, Center MM, et al. Global cancer statistics. CA Cancer J Clin.61:69-90.

2 Zhang Z, Zhang X. Salt taste preference, sodium intake and gastric cancer in China. Asian Pac J Cancer Prev.12:1207-1210.

3 Kim J, Park S, Nam BH. Gastric cancer and salt preference: a population-based cohort study in Korea. Am J Clin Nutr.91:1289-1293.

4 D'Elia L, Rossi G, Ippolito R, Cappuccio FP, Strazzullo P. Habitual salt intake and risk of gastric cancer: a meta-analysis of prospective studies. Clin Nutr.31:489-498.

5 Park JH, Kim YC, Koo HS, et al. Estimated amount of 24-hour urine sodium excretion is positively correlated with stomach and breast cancer prevalence in Korea. J Korean Med Sci.29 Suppl 2:S131-138.

6 Umesawa M, Iso H, Fujino Y, Kikuchi S, Tamakoshi A. Salty Food Preference and Intake and Risk of Gastric Cancer: The JACC Study. J Epidemiol.26:92-97.

7 Park Y-h, Chung S-J. A Comparison of Sources of Sodium and Potassium Intake by Gender, Age and Regions in Koreans: Korea National Health and Nutrition Examination Survey (KNHANES) 2010-2012. Korean J Community Nutr.21:558-573. 
8 Kong JS, Lee YK, Kim MK, et al. Estimation model for habitual 24-hour urinary-sodium excretion using simple questionnaires from normotensive Koreans. PLoS One.13:e0192588.

9 Dias-Neto M, Pintalhao M, Ferreira M, Lunet N. Salt intake and risk of gastric intestinal metaplasia: systematic review and meta-analysis. Nutr Cancer.62:133-147.

10 Kawasaki T, Itoh K, Uezono K, Sasaki H. A simple method for estimating $24 \mathrm{~h}$ urinary sodium and potassium excretion from second morning voiding urine specimen in adults. Clin Exp Pharmacol Physiol. 1993;20:7-14.

11 Petersen KS, Wu JHY, Webster J, et al. Estimating mean change in population salt intake using spot urine samples. Int J Epidemiol.46:1542-1550.

12 Tanaka T, Okamura T, Miura K, et al. A simple method to estimate populational 24-h urinary sodium and potassium excretion using a casual urine specimen. J Hum Hypertens. 2002;16:97-103.

13 Jedrusik P, Symonides B, Gaciong Z. Comparison of three formulas to estimate 24-hour urinary sodium and potassium excretion in patients hospitalized in a hypertension unit. J Am Soc Hypertens. 2018;12:457-469.

14 Park JH, Kim YC, Koo HS, et al. Estimated amount of 24-hour urine sodium excretion is positively correlated with stomach and breast cancer prevalence in Korea. J Korean Med Sci. 2014;29 Suppl 2:S131138.

15 INTERSALT Study an international co-operative study on the relation of blood pressure to electrolyte excretion in populations. I. Design and methods. The INTERSALT Co-operative Research Group. J Hypertens. 1986;4:781-787.

16 Nam HS, Kim HW, Choi CW, et al. Characteristics of overlooked synchronous gastric epithelial neoplasia after endoscopic submucosal dissection. Medicine (Baltimore). 2018;97:e12536.

17 Lee $\mathrm{HH}$, Park JM, Lim CH, et al. The impact of pre-resection endoscopic examination time on the rate of synchronous gastric neoplasms missed during endoscopic treatment. Surg Endosc. 2017;31:39523960 .

$18 \mathrm{Kim} \mathrm{HH}, \mathrm{Kim} \mathrm{JH}, \mathrm{Kim} \mathrm{GH}$, et al. Causes of missed synchronous gastric epithelial neoplasms with endoscopic submucosal dissection: a multicenter study. Scand J Gastroenterol. 2013;48:1339-1346.

19 Yoo JH, Shin SJ, Lee KM, et al. How can we predict the presence of missed synchronous lesions after endoscopic submucosal dissection for early gastric cancers or gastric adenomas? J Clin Gastroenterol. 2013;47:e17-22.

20 Yusefi AR, Bagheri Lankarani K, Bastani P, Radinmanesh M, Kavosi Z. Risk Factors for Gastric Cancer: A Systematic Review. Asian Pac J Cancer Prev.19:591-603. 
21 Nitta T, Egashira Y, Akutagawa H, et al. Study of clinicopathological factors associated with the occurrence of synchronous multiple gastric carcinomas. Gastric Cancer. 2009;12:23-30.

22 Fedeli G, Cannizzaro O, Gambassi G, et al. Increased prevalence of intestinal metaplasia in the gastric mucosa of the elderly: clinical implications. Ann Ital Med Int. 1990;5:26-30.

23 Siegel R, Naishadham D, Jemal A. Cancer statistics, 2013. CA Cancer J Clin. 2013;63:11-30.

24 Lindblad M, Rodriguez LA, Lagergren J. Body mass, tobacco and alcohol and risk of esophageal, gastric cardia, and gastric non-cardia adenocarcinoma among men and women in a nested case-control study. Cancer Causes Control. 2005;16:285-294.

25 Freedman ND, Derakhshan MH, Abnet CC, et al. Male predominance of upper gastrointestinal adenocarcinoma cannot be explained by differences in tobacco smoking in men versus women. Eur $\mathrm{J}$ Cancer. 2010;46:2473-2478.

26 Camargo MC, Goto Y, Zabaleta J, et al. Sex hormones, hormonal interventions, and gastric cancer risk: a meta-analysis. Cancer Epidemiol Biomarkers Prev. 2012;21:20-38.

27 Lee SA, Kang D, Shim KN, et al. Effect of diet and Helicobacter pylori infection to the risk of early gastric cancer. J Epidemiol. 2003;13:162-168.

28 Song JH, Kim YS, Heo NJ, et al. High Salt Intake Is Associated with Atrophic Gastritis with Intestinal Metaplasia. Cancer Epidemiol Biomarkers Prev.26:1133-1138.

29 He J, Gu D, Chen J, et al. Gender difference in blood pressure responses to dietary sodium intervention in the GenSalt study. J Hypertens. 2009;27:48-54.

30 Shukri MZ, Tan JW, Manosroi W, et al. Biological Sex Modulates the Adrenal and Blood Pressure Responses to Angiotensin II. Hypertension.71:1083-1090.

31 Manosroi W, Tan JW, Rariy CM, et al. The Association of Estrogen Receptor-beta Gene Variation With Salt-Sensitive Blood Pressure. J Clin Endocrinol Metab.102:4124-4135.

32 Kelly TN, Rebholz CM, Gu D, et al. Analysis of sex hormone genes reveals gender differences in the genetic etiology of blood pressure salt sensitivity: the GenSalt study. Am J Hypertens.26:191-200.

$33 \mathrm{Kim} \mathrm{HJ}, \mathrm{Kim} \mathrm{N}, \mathrm{Kim} \mathrm{HY}$, et al. Relationship between body mass index and the risk of early gastric cancer and dysplasia regardless of Helicobacter pylori infection. Gastric Cancer. 2015;18:762-773.

34 Huang YK, Kang WM, Ma ZQ, et al. Body mass index, serum total cholesterol, and risk of gastric high-grade dysplasia: A case-control study among Chinese adults. Medicine (Baltimore).95:e4730.

35 O'Donnell M, Mente A, Rangarajan S, et al. Urinary sodium and potassium excretion, mortality, and cardiovascular events. N Engl J Med.371:612-623. 
36 Pfister R, Michels G, Sharp SJ, et al. Estimated urinary sodium excretion and risk of heart failure in men and women in the EPIC-Norfolk study. Eur J Heart Fail.16:394-402.

37 Huh JH, Lee KJ, Lim JS, et al. High Dietary Sodium Intake Assessed by Estimated 24-h Urinary Sodium Excretion Is Associated with NAFLD and Hepatic Fibrosis. PLoS One.10:e0143222.

38 Won JC, Hong JW, Noh JH, Kim DJ. Association Between Estimated 24-h Urinary Sodium Excretion and Metabolic Syndrome in Korean Adults: The 2009 to 2011 Korea National Health and Nutrition Examination Survey. Medicine (Baltimore).95:e3153.

39 Han SY, Hong JW, Noh JH, Kim DJ. Association of the estimated 24-h urinary sodium excretion with albuminuria in adult koreans: the 2011 Korea National Health and Nutrition Examination Survey. PLoS One.9:e109073.

40 Hong JW, Noh JH, Kim DJ. Factors Associated With High Sodium Intake Based on Estimated 24Hour Urinary Sodium Excretion: The 2009-2011 Korea National Health and Nutrition Examination Survey. Medicine (Baltimore). 2016;95:e2864.

41 Mente A, O'Donnell M, Rangarajan S, et al. Urinary sodium excretion, blood pressure, cardiovascular disease, and mortality: a community-level prospective epidemiological cohort study. Lancet. 2018;392:496-506.

42 Nam GE, Kim SM, Choi MK, et al. Association between 24-h urinary sodium excretion and obesity in Korean adults: A multicenter study. Nutrition. 2017;41:113-119.

43 Seo JE, Lee HS, Lee SW, et al. The Association between Urinary Sodium Excretion and Metabolic Syndrome in Korean Adults from the 2010-2011 Korean National Health and Nutrition Examination Survey. Korean J Fam Med. 2017;38:199-205.

\section{Figures}




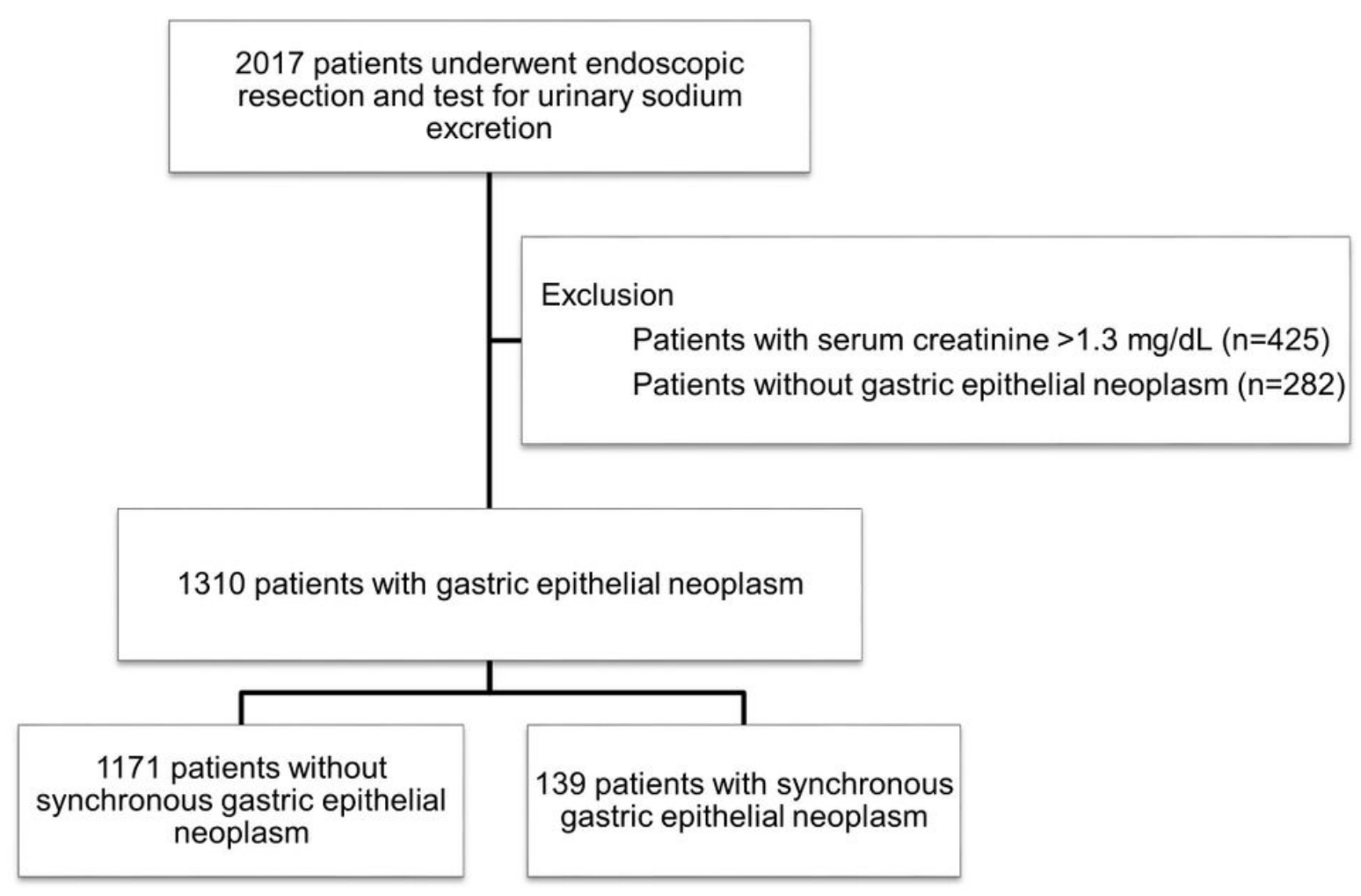

Figure 1

Flow chart of the study. 


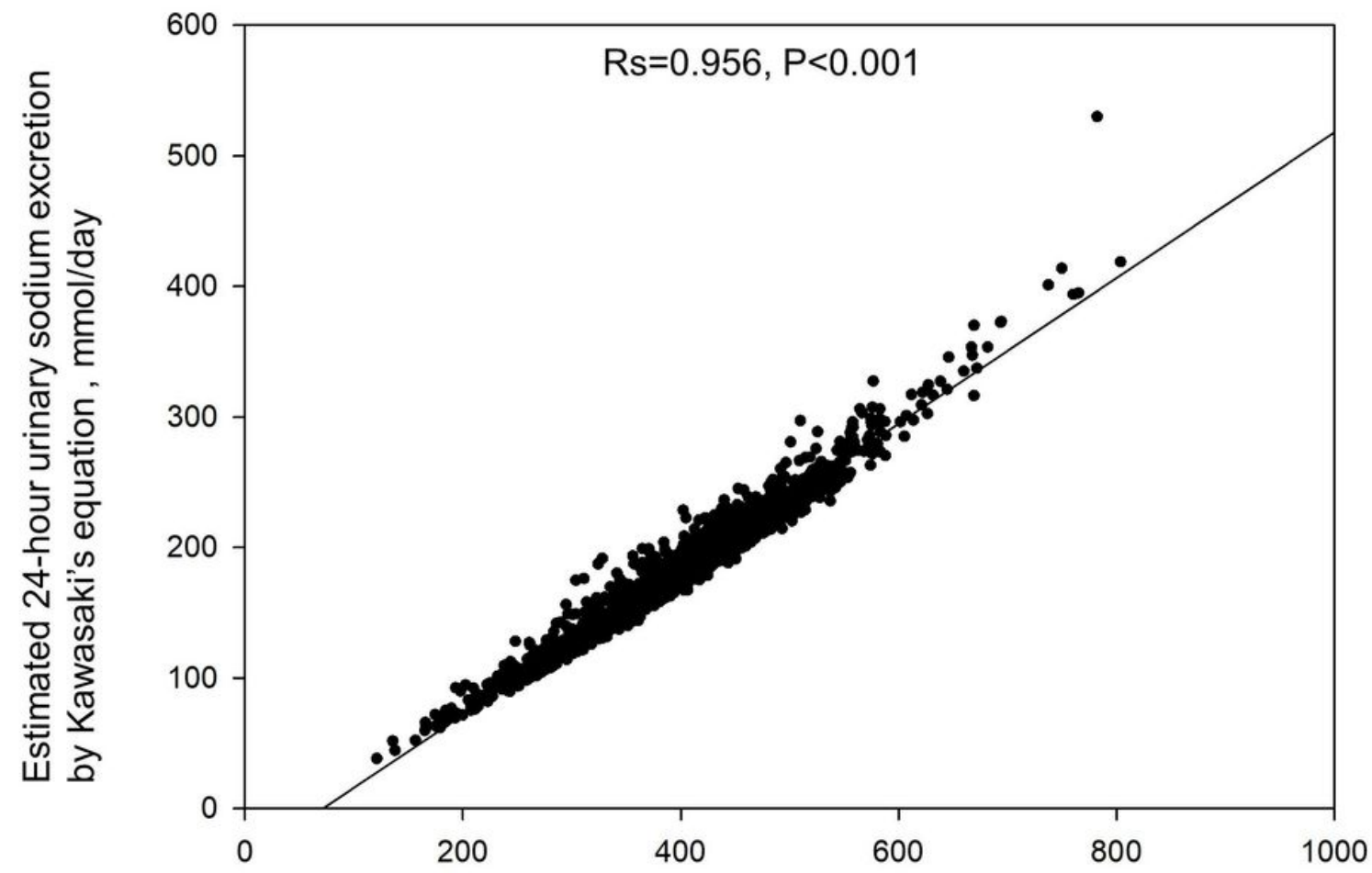

Estimated 24-hour urinary sodium excretion by Tanaka's equation , mmol/day

\section{Figure 2}

Spearman correlation between 'estimated 24-hour urinary sodium excretion' by Tanaka's equation and 'estimated 24-hour urinary sodium excretion' by Kawasaki' equation and (Spearman correlation coefficient, Rs $=0.956 ; \mathrm{P}<0.001)$. 